\title{
The scale-inuariant properties of the citation-based performance of internationally co-authored articles
}

\author{
Guillermo Armando Ronda-Pupo \\ Departamento de Administración. \\ Universidad Católica del Norte. Avenida Angamos. \\ № 0610. Antofagasta, ZIP: 1270709, CHILE. \\ Departamento de Turismo \\ Universidad de Holguín, CUBA \\ e-mail: gronda@ucn.cl
}

\begin{abstract}
The aim of this paper is to determine the scale-invariant properties of the citation-based performance of internationally co-authored articles on Management Information Systems (MIS). A total of 20, 485 articles which received a total of 432,386 citations were analyzed. Collaborative articles accounted for 83 percent of the papers. Citation-based performance and international collaborative papers exhibited a power-law correlation with a scaling exponent of $1.28 \pm 0.05$. Citations to MIS articles increased $2^{1.28}$ or 2.42 with a doubling of the number of internationally collaborative papers. The scaling exponent for the power-law correlation for domestic collaborative papers was $1.22 \pm 0.04$ indicating that citations grew by $2^{1.22}$ or 2.32 times when the number of domestic papers doubled. MIS articles published through international collaboration show a stronger Matthew Effect than those published through domestic collaboration. International collaborative papers were further analyzed by global regions. The papers that were internationally collaborative with authors being from different global regions have a scaling exponent for the power-law correlation with citation-based performance of $1.25 \pm 0.06$. This exponent shows that citations grew $2^{1.26 \pm 0.06}$ or 2.37 times when the number of these inter-regional papers doubled. Those papers that were internationally collaborative with the authors being from the same global region (intra-regional) have a scaling exponent for the power-law correlation with citation-based performance of $1.56 \pm 0.14$. This performance demonstrates that citations grew $2^{1.56 \pm 0.14}$ or 2.94 times when the number of intra-regional papers doubled. This indicates that the Matthew Effect is stronger for intra-regional collaborative papers than for interregional ones.
\end{abstract}

Keywords: Allometry; Academic collaboration; Complex innovation system; Citation-based performance; Management Information Systems (MIS)

\section{INTRODUCTION}

In recent years, the study of complex systems in a unified framework has been recognized as a new scientific discipline. Some even refer to it as the ultimate interdisciplinary field (BarYam 1997). A complex system dynamically evolves in non-linear ways giving it unique properties that distinguish it from other systems. In particular, a common signature of complex systems is scale invariant emergent properties. A scale invariant property can be identified because it is solely described by a power law function in the form, $f(x)=k x^{\alpha}$ where the exponent, $\alpha$, is a measure of the system's scale invariance (Katz 2016). 
The global research system is an example of a complex innovation system (Katz 2016). Peerreviewed publications containing knowledge in specific areas are a characteristic output of such a system. The number of citations to these articles is an indirect measure of the impact the knowledge contained in these publications has on the research community. Received citations are used to illustrate how scale invariant properties can be identified and quantified (Katz 2016).

Complexity also involves an interplay between cooperation and competition (Baranger 2013). The process of generating and disseminating new knowledge in scientific disciplines fosters the emergence of collaborative networks between researchers, institutions and countries that at the same time compete for limited resources to do relevant research. As this process gets larger, a complex network emerges. This network is composed of a large number of interconnected nodes whose connectivity (node degree) has a power law probability distribution characterized by $p(x)=k x^{-\alpha}$ for $x \geq x_{\min }{ }^{1}$ (Katz 2016; Newman 2004). The exponent, $\alpha$, called the scaling factor, and $k$ are constants for a given network. For most real-world networks the magnitude of the scaling factor is in the range of $2<\alpha<$ 3 (Clauset, Shalizi and Newman 2009). Citation networks, which are used to prepare measures of the impact of published research, are usually considered to be complex networks with $\alpha \approx 3.0$ (Redner 1996).

Determining the scale invariant properties of the relationship between citation-based performance (CBP) and international/domestic collaboration will provide information to the scientometric scientific community interested in the study of co-authorship networks of academic disciplines. The research questions for the study are:

(a) Does the relationship between CBP and international collaboration patterns show scale invariant properties with $\alpha>1.0$ ?

(b) Is the Matthew Effect for CBP for internationally collaborative articles stronger than for domestic collaborative articles?

(c) Is the Matthew Effect for CBP for inter-regional collaborative articles stronger than for intra-regional collaborative articles?

\section{MANAGEMENT INFORMATION SYSTEMS AS A CASE STUDY}

Management Information Systems (MIS) is a young academic research discipline. Its beginnings date back to early 1980s (DeLone and McLean 1992). It emerged as an interdisciplinary field from the conjunction of computer science, management, and the social sciences (Cunningham and Dillon 1997). Since its inception, MIS has focused on the creation and dissemination of knowledge on the use of information technologies to foster the effectiveness of decision making processes at all levels in organizations.

MIS as a research discipline has evidenced a sustained growth over the past three decades. This is highlighted by the fact that the number of MIS journals indexed in the Web of Science (WOS) has increased substantially in the past thirty years. It has grown from 23 MIS journals in 1980-1990 to 60 by 2012 (Ronda-Pupo and Katz 2017a). Furthermore, the number of MIS articles published in WOS grew exponentially from just 64 articles in 1984 to 1531 articles by the end of 2012. The number of multi-authored papers in MIS is also showing an upward trend (Cunningham and Dillon 1997).

\footnotetext{
${ }^{1}$ The $x_{\min }$ value is the highest probability point in the distribution where the power-law begins.
} 
The increase in the amount of knowledge disseminated through MIS journals permits the mapping of the structure of the international collaboration network of the MIS scientific community and the assessment of the scale invariant properties of the relationship between the citation-based impact of articles on MIS and their international collaborative patterns. Also, it favors the study of scale invariant emergent properties of international collaborative research networks in this research area. The study of scale invariance properties of coauthored articles on the MIS discipline has not been conducted. This will shed light on the advantages of academic collaboration to foster the citation impact of papers of MIS as a young academic research discipline.

\section{BACKGROUND AND HYPOTHESIS}

The number of articles analyzing the relationship between CBP and international scientific collaboration has grown significantly in the past two years. On average international collaborative publications have a higher citation impact than domestic ones (Wang, Thijs, and Glänzel 2015; Puuska, Muhonen, and Leino 2014). The average citations per paper over the period 1996-2003 for some Asiatic universities increased up to 5.0 citations per paper through international collaboration (Khor and Yu 2016). Latin American articles in management published through international collaboration had 1.59 times more impact than those published through domestic collaboration (Ronda-Pupo et al. 2015). Conversely, however, American scientists publishing in Nature and Science had no additional impact benefit from international collaboration (Rousseau and Ding 2016).

All the mentioned studies used average based scientometric indicators to analyze collaboration. Studies of science systems have shown that they are complex, adaptive systems with emergent properties frequently characterized by power law distributions and/or correlations (Katz 2012; Gao and Guan 2009).

van Raan (2013, p.1) wrote: "Cumulative effects imply a nonlinear increase of impact with increasing size, demonstrated by the finding that the number of citations as a function of number of publications exhibits a power law dependence with an exponent larger than 1". Recently it was found that collaboration patterns and citations in articles in management journals follow a power law correlation, suggesting that the relationship between CBP and international/domestic collaboration patterns will also follow a power-law correlation (Ronda-Pupo and Katz 2015).

H1: The CBP of international collaborative articles on MIS exhibits scale invariant properties with an exponent $\alpha>1.0$.

The term Matthew Effect has its root in the Gibrat's law or Gibrat's rule of proportionate growth or the law of proportionate effect (Gibrat 1931). In scientometrics the term Matthew Effect has become popular through the work of Merton (1968). The Matthew Effect in science is the common observation that in any given scientific research area most papers do not receive any or only a few citations while a small minority of papers are very heavily cited and become the core of the citation network. This behavior tends to produce heavy tailed distributions which are described by a power law distribution (de Solla-Price 1976).

A power law correlation is frequently found between impact (measured using citations) and size (measured using papers) across members of a group (e.g. journals, fields, institutions, countries, etc.). The exponent of the power law correlation is a measure of the magnitude 
of the Matthew Effect (van Raan 2013; Katz 1999; Ronda-Pupo and Katz 2017b) illustrated in the following manner. Given a scaling correlation $f(x)=k x^{\alpha}$ then for $\alpha>1 f(x)$ increases non-linearly with $x$ indicative of a cumulative advantage effect. Now consider we find $f(x)^{\prime}=k x^{\alpha \prime}$ where $f(x)^{\prime}>f(x)$ indicating that the cumulative advantage for $f(x)^{\prime}$ is larger than the cumulative advantage of $f(x)$. This can be true if and only if $\alpha^{\prime}>\alpha$, thus the exponent is proportional to an increase in the cumulative advantage or Matthew Effect (Ronda-Pupo and Katz 2017b). According to this behavior we will test the following hypothesis:

H2: The Matthew Effect for CBP for international collaborative articles will be stronger than for domestic collaborative articles.

H3: The Matthew Effect for CBP for international collaborative articles that have intraregional collaboration will be stronger than those with inter-regional collaboration.

\section{METHOD}

The power-law model was used in the study. Equation 1 shows the mathematical formulation of the model.

$$
C B P=k C^{\alpha}
$$

Where $C$ is the number of collaborative (international or domestic) papers, $\log (k)$ is a normalization constant, (the intercept in the log-log regression) and $\alpha$ is the scaling factor (slope of the log-log regression line).

\section{Definition of Variables in the Model}

Table 1 shows the variables and their conceptual definitions. The CBP of each paper is the total number of citations in the time frame analyzed. Information about international or domestic collaboration patterns was determined using the AU (Author) and C1 (Addresses) fields for each document in the Web of Science database. $A U=1$ is a single author paper and $A U>1$ indicates a multi-author paper.

Table 1: Variables and their Conceptual Definitions

\begin{tabular}{ll}
\hline \hline \multicolumn{1}{c}{ Variables } & \multicolumn{1}{c}{ Conceptual Definition } \\
\hline \hline $\begin{array}{l}\text { Citation-Based Performance } \\
\text { International collaboration }\end{array}$ & The number of citations received by each paper. \\
Domestic collaboration & $\begin{array}{l}\text { The number of articles on MIS co-authored by scientists from } \\
\text { different countries. } \\
\text { The number of articles on MIS co-authored by scientists all } \\
\text { working in the same country. }\end{array}$ \\
Intra- regional collaboration & $\begin{array}{l}\text { The number of articles on MIS co-authored by scientists working } \\
\text { in different countries within the same region. } \\
\text { Inter-regional collaboration }\end{array}$ \\
& $\begin{array}{l}\text { The number of articles on MIS co-authored by scientists from } \\
\text { different regions. See regions in Appendix } 2 .\end{array}$ \\
\hline
\end{tabular}




\section{Mapping the International MIS Collaborative Network' Structure}

The international and regional collaborative structures were determined using Pajek software. The position of each country within these structures was determined using degree centrality (Ronda-Pupo and Guerras-Martín 2016). The degree centrality of a country, denoted by $C^{\prime} D_{(n i)}$ is the number of countries that are connected to it (Wasserman and Faust 2009). The Wasserman and Faust (2009, p.179) method is used to calculate the degree centrality given by the following equation:

$$
C^{\prime} D_{(n i)}=\frac{d(n i)}{g-1}
$$

where $C^{\prime} D_{(n i)}$ stands for degree centrality of country $(n i), d(n i)$ is the number of countries linked to the country $n i$, and $g-1$ is the total sum of countries in the network' structure except for the country $n i_{\text {i. }}$.

Each country's degree centrality was calculated using an adjacency matrix. The value of the link between each pair of countries was adjusted according to a country's participation in a paper. For example, a country that participated in an article in collaboration with two other countries received $1 / 3$ of the credit for the article. Pajek software (Batagelj and Mrvar 1998) was used to graphically depict the structure of the international collaboration network using adjacency. Loops were removed before calculating degree centrality for each country in the network.

The degree centrality values obtained for each country was within the range of 0.00 to 1.00 . This range was stratified into three thresholds. A degree centrality of 0.00 to 0.33 located countries that are in the network periphery. Countries with a degree centrality between 0.34 and 0.66 are in the network semi-periphery. Finally, countries that belong to the core of the network had a degree centrality between 0.67 and 1.00 .

\section{Data Source}

The data for the study consists of documents (articles including proceedings, papers and reviews) published in 58 Management Information System journals (Appendix 1) between 1990 and 2010 inclusive in Clarivate Analytics Web of Science ${ }^{\mathrm{TM}}$ Core Collection database. These publication types were used for two reasons: (a) they are peer-reviewed; and, (b) they are a primary route for disseminating new knowledge in most scientific disciplines (Adams and Gurney 2013).

Herranz and Ruiz-Castillo (2012) reported that about 42 percent of the articles indexed in the Web of Science are assigned between two to six subfields. This situation is a drawback in scientometric studies using citation counts to papers of a research discipline. To overcome this limitation, the Science Metrix journal classification ontology was used. (Archambault, Beauchesne and Caruso 2015). According to the Science Metrix journal classification scheme, Information Systems is a sub-field within the field of Information and Communication Technologies of the domain Applied Sciences.

The advantages of using the Science Metrix journal classification ontology are: (a) it is available under a creative common license readily accessible to everyone in the bibliometric community; (b) many knowledgeable bibliometricians have contributed to its development; (c) the domains/fields/subfields are based on existing journal classifications; (d) their groupings of journals act as attractors for journals in the new classification; and (e) individual journals are assigned to single, mutually exclusive domain/field/subfield using a hybrid 
approach combining algorithmic methods and expert judgment (Ronda-Pupo and Katz 2017b).

Clarivate Analytics' Web of Science ${ }^{\mathrm{TM}}$ Core Collection was used to retrieve the data and the following parameters were used: Tag Advance search $\mathrm{SO}=$ 'Journal Name', refined by Document Types, (Article OR Review), Timespan $=1990-2010$, Indexes = SSCI-EXPANDED, $\mathrm{SSCl}, \mathrm{A \& HCl}$. Bibliographic information for each paper was downloaded into a tab-delimited text file and yearly citation counts were downloaded to an Excel file. These files were merged by using the DOI of each article. Finally, the information was stored in a Structured Query Language (SQL) database for analysis.

\section{RESULTS}

The search on the Web of Science retrieved 37,291 documents yielding 28,776 articles and reviews. 8,291 papers with incomplete address fields were excluded because it was not possible to code them as either international or domestic. Table 2 shows the number of papers according to collaborative type. Highlights are summarized as follows:

(a) 83 percent of articles and reviews on MIS were co-authored. These papers accounted for 86 percent of all citations.

(b) Of the co-authored papers, 81 percent involve a domestic collaboration and these papers accounted for 75 percent of the citations of co-authored papers while 19 percent were international and accounted for 25 percent of the citations.

(c) Of the international collaborative papers, 75 percent involved an inter-regional collaboration that accounted for 74 percent of their citations. 25 percent were intraregional and accounted for $26 \%$ percent of the citations.

Table 2: Number of Articles According to Collaboration Patterns

\begin{tabular}{lcccc}
\hline \hline Collaboration Pattern & \# Papers & \% & \# Citations & $\%$ \\
\hline \hline Single-authored & 3,529 & $17 \%$ & 58,403 & $14 \%$ \\
Co-authored & 16,956 & $83 \%$ & 373,983 & $86 \%$ \\
\hline Domestic Co-authored & 13,692 & $81 \%$ & 282,196 & $75 \%$ \\
International Co-authored & 3,264 & $19 \%$ & 91,787 & $25 \%$ \\
\hline Intra-regional International & 816 & $25 \%$ & 24,145 & $26 \%$ \\
Inter-regional International & 2,448 & $75 \%$ & 67,642 & $74 \%$ \\
\hline \hline
\end{tabular}

\section{The International Collaboration Network of MIS Research}

Figure 1 shows the international collaboration network of MIS research. It consists of 98 countries. The structure of the network suggests a core-periphery structure. The United States of America is in the core of the network with the highest degree centrality value. In the semi-periphery positions are Austria, Canada, France, Germany, Italy, Japan, Netherlands, and UK with degree centrality values between 0.33 and 0.66 . The periphery consists of the other countries with a degree centrality below 0.33 . 


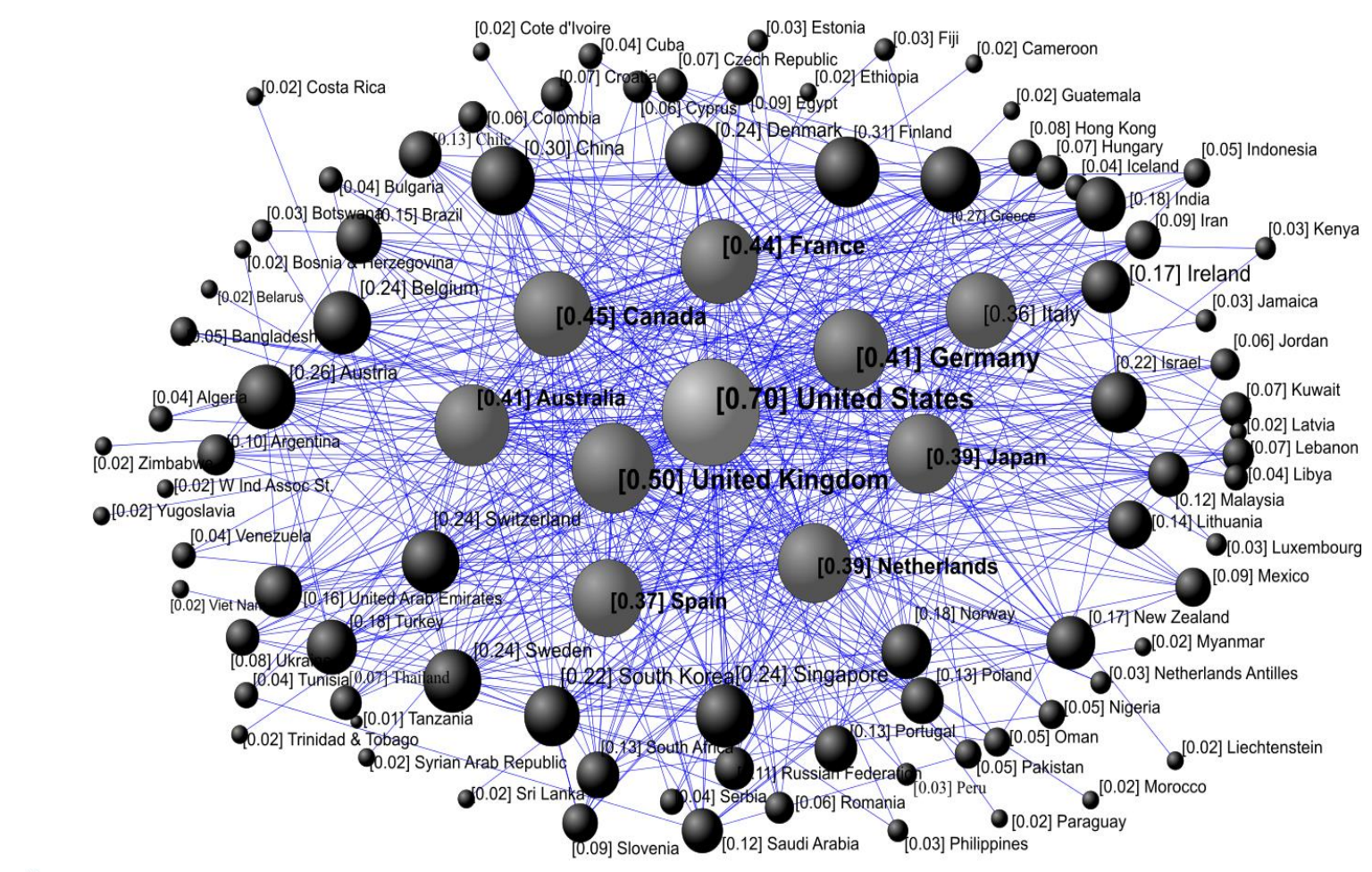

Figure 1: International Collaboration Network on MIS Research

Note: Numbers between brackets are the degree centrality of countries. Loops were removed

The countries with higher degree centrality are the ones with higher scientific production in MIS and also the ones with a higher citation performance. This result suggests that the more a national science system disseminates the knowledge it produces, the more importance it gains in the international network and thus attracts smaller science systems that will preferentially attach to it.

The process of preferential attachment may increase the absorptive capacities of the more central national science community and thus further attract other small science systems to the system. This phenomenon leads to an increase in degree centrality as (Ronda-Pupo and Guerras-Martín 2016) found for the inter-institutional collaboration networks in the management discipline. Recently, Ronda-Pupo and Katz (2017a) found the citation-based performance and degree centrality of countries exhibited a power-law correlation with a scaling exponent of $1.22 \pm 0.04$. Citations to the articles of a country in MIS tended to increase $2^{1.22}$ or 2.33 times each time it doubles its degree centrality in the international MIS collaborative network.

Figure 2 shows the inter-regional collaboration network in MIS research. The Northern American region is the most central region on MIS research, followed by Western Europe and the Asiatic region. These regions are the ones with higher economic growth in the time frame analyzed. The African countries had only a few participants in the international collaboration network. This lower level of international collaboration could be a consequence of the small economic size and scarcity of scientific development in Africa. Latin America, Eastern Europe and the Middle East have scarce participation in the interregional network. These regions have experienced profound changes in the socio-political 
and economic systems in the past 30 years. This has had an impact on their science systems and their scientific production on MIS topics.

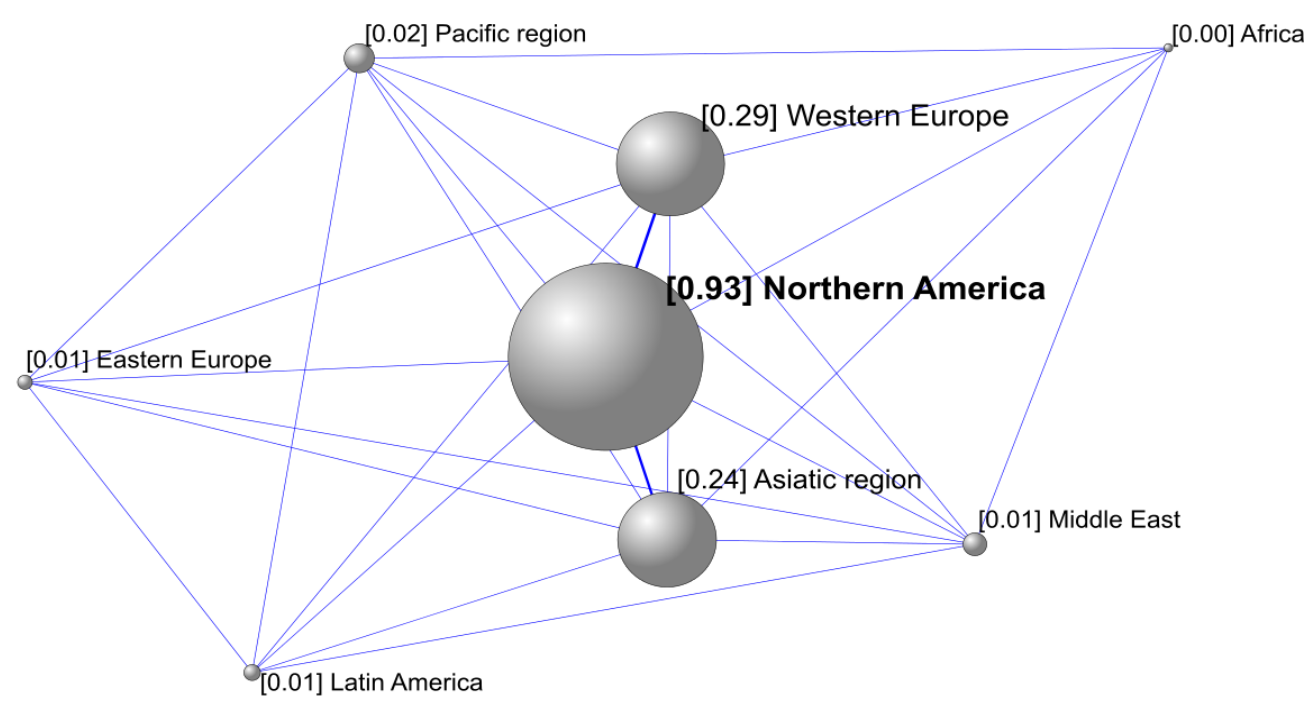

Figure 2: Inter-regional Collaboration Network on MIS Research

Note: Numbers between brackets are the degree centrality of regions. Loops were removed.

\section{The Power Law Relationship between CBP and International Collaboration Patterns in MIS Articles}

Table 3 and Figure 3 shows the results of the analysis of the power-law correlations. The exponent for the scaling correlation between CBP and international collaborative papers is $1.28 \pm 0.05$ suggesting that a doubling in the number of international collaborative papers on MIS would increase the number of citations by $2^{1.28 \pm 0.05}$ or 2.42 times. The exponent for the scaling correlation between CBP and domestic collaborative papers is $1.22 \pm 0.04$. This exponent suggests that a doubling in the number of domestic collaborative papers on MIS would increase the number of citations by $2^{1.22 \pm 0.04}$ or 2.32 times. International collaboration has a higher cumulative advantage and hence a stronger Matthew Effect than domestic collaboration.

Table 3: Scaling Exponents for the Power Law Correlations.

\begin{tabular}{lccccc}
\hline \hline Collaboration Pattern & Alpha & $\boldsymbol{S D}$ & $\boldsymbol{R}^{\mathbf{2}}$ & $\boldsymbol{t}$ & $\boldsymbol{P}$ \\
\hline \hline Overall & 1.28 & 0.04 & 0.98 & 132.17 & 0.00 \\
Single-authored & 1.51 & 0.08 & 0.95 & 46.21 & 0.00 \\
Co-authored & 1.24 & 0.04 & 0.98 & 23.60 & 0.00 \\
Domestic Co-authored & 1.22 & 0.04 & 0.98 & 89.53 & 0.00 \\
International Co-authored & 1.28 & 0.05 & 0.98 & 95.08 & 0.00 \\
Intra-regional International & 1.56 & 0.14 & 0.88 & 17.75 & 0.00 \\
Inter-regional International & 1.25 & 0.06 & 0.96 & 59.66 & 0.00 \\
\hline \hline
\end{tabular}

Note: $S D$ is the standard error for alpha 
The exponent for the scaling correlation between $\mathrm{CBP}$ and inter-regional collaborative papers is $1.25 \pm 0.06$ showing that a doubling in the number of inter-regional collaborative papers on MIS would increase the number of citations by $2^{1.25 \pm 0.06}$ or 2.37 times. The exponent for the scaling correlation between CBP and intra-regional collaborative papers is $1.56 \pm 0.14$. This exponent shows that a doubling in the number of intra-regional collaborative papers on MIS would increase the number of citations by $2^{1.56 \pm 0.14}$ or 2.94 times. Intra-regional collaboration has a stronger Matthew Effect than inter-regional collaboration.

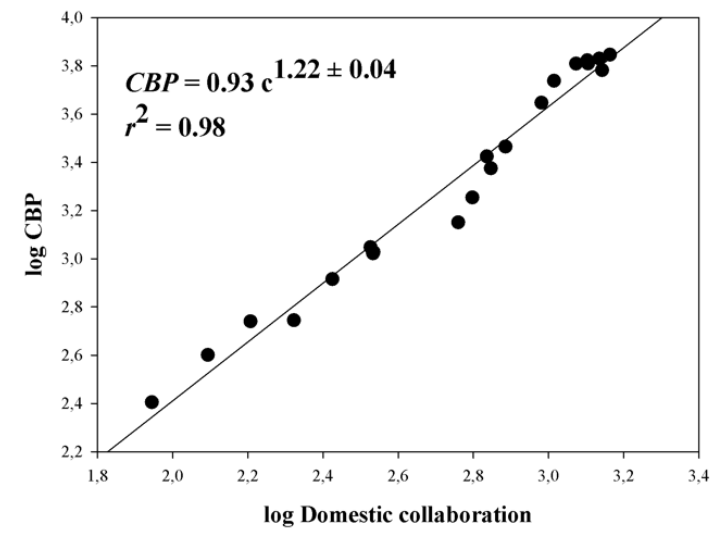

a-Domestic collaboration.

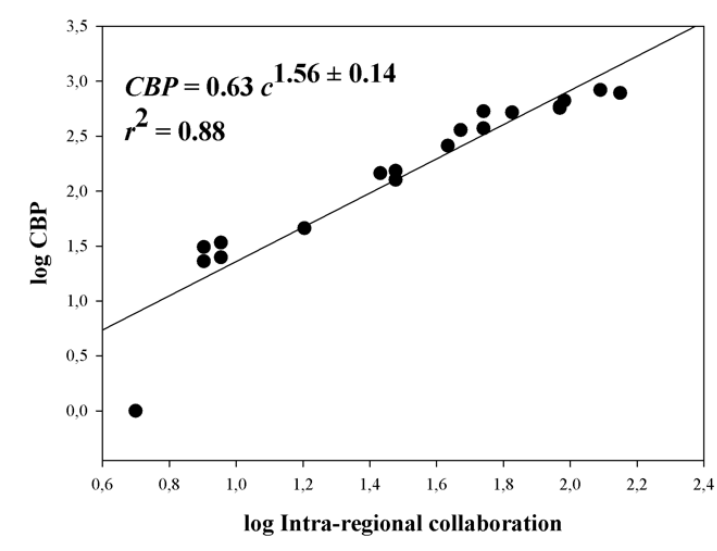

c-Intra-regional collaboration.

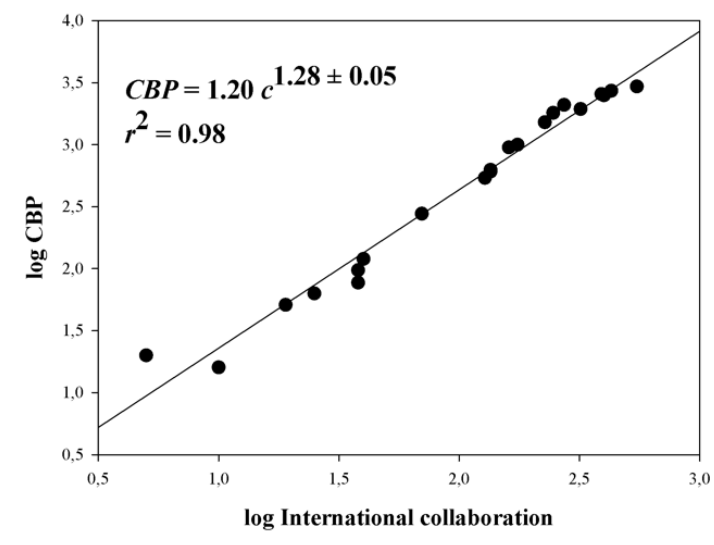

b -International collaboration.

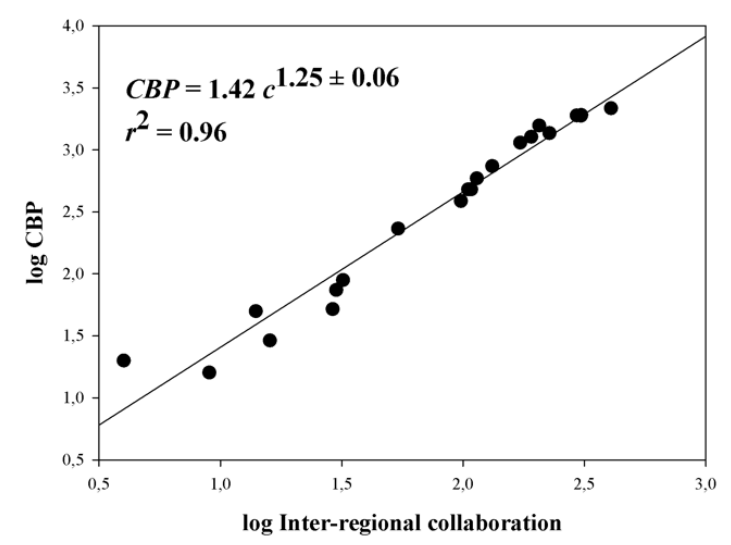

d-Inter-regional collaboration.

Figure 3: Power Law Correlations.

\section{DISCUSSION AND CONCLUSION}

Scientific recognition of the international collaborative network in MIS research is described by scale invariant properties. The CBP of international collaborative articles in MIS increases $2^{1.28 \pm 0.05}$ or 2.42 times when the number of international collaborative papers doubles. On the other hand, the CBP of domestic collaborative articles on MIS increases $2^{1.22 \pm 0.04}$ or 2.32 times when the number of domestic collaborative papers doubles. The Matthew Effect of CBP for international collaborative papers in MIS is stronger than for domestic collaborative papers. 
Intra-regional collaborative articles have a power law correlation with the CBP. The scaling exponent was $1.56 \pm 0.14$ suggesting that the CBP increases $2^{1.56 \pm 0.14}$ or 2.94 times when the number of intra-regional collaborative papers doubles. On the other hand, the CBP of MIS for inter-regional collaborative articles increases $2^{1.25 \pm 0.06}$ or 2.37 times when the number of inter-regional collaborative papers doubles. The Matthew Effect of CBP for intraregional collaborative papers is stronger than for inter-regional collaborative papers. This may be due to a variety of factors including working on common local problems and the effects of geographical proximity (Katz 1994).

Small science systems may be able to enhance their absorptive capacities and intellectual capital by increasing their collaborative activities with top-performance systems. This collaboration would also give small science systems greater access to leading edge technologies and knowledge that may increase their international visibility. Top-performing science systems may gain by increasing their degree centrality enhancing their knowledge dissemination channels.

Authors, managers and policy makers should consider the Matthew Effect when deciding what forms of collaboration are most likely to have a significant impact. For example, singleauthored academic MIS publications exhibit an inverse Matthew Effect. In other words, a doubling in the number of papers published produces less than a doubling of CBP in MIS research. The impact of single author MIS papers is less than multi-authored papers irrespective of journal size.

The Matthew effect of CBP varies with the type of co-authorship. Domestic collaboration articles have a small, almost linear, Matthew Effect while International collaboration is significantly larger. With-in International collaboration there is also differences. Interregional collaboration is also significantly greater than domestic collaboration but the most noteworthy is intra-regional collaboration which has the largest Matthew Effect. In other words, multi-authored intra-regionally MIS research articles have, on average, the greatest impact irrespective of the size of the journal.

\section{ACKNOWLEDGEMENT}

This research was financed by Universidad Católica del Norte, Chile. Grant Number: 01-01230203-10301440-NADA. We thank the anonymous reviewer for his/her interesting comments on a previous version of the manuscript. We thank Professor J. Sylvan Katz for sharing ideas on the methods for constructing scale invariant indicators for scientometric evaluation purposes, and Professor Ronald Rousseau for his interesting suggestions that contributed to the improvement of the paper.

\section{REFERENCES}

Adams, J. and Gurney, K. 2013. Leading research economies in a changing knowledge network. Spain. Thomson Reuters, accessed 10-09-2015. Available at: http:www.researchanalytics.thomsonreuters.com/grr

Archambault, É., Beauchesne, O. H. and Caruso, J. 2015. Towards a Multilingual, Comprehensive and Open Scientific Journal Ontology. In Proceedings of the 13th international conference of the international society for scientometrics and informetrics (pp. 66-77). South Africa: Durban, accessed 03-30-2016. Available at: 
http://www.sciencemetrix.com/pdf/Towards_a_Multilingual_Comprehensive_and_Op en.pdf

Bar-Yam, Y. 1997. Dynamics of complex systems. Massachussetts: Addison Wesley Longman Inc.

Baranger, M. 2013. Chaos, Complexity, and Entropy A physics talk for non-physicists. Available at: http://necsi.edu/projects/baranger/cce.pdf

Batagelj, V. and Mrvar, A. 1998. Pajek - Program for large network analysis. Connections, Vol. 21 no. 2: 47-57.

Clauset, A., Shalizi, C. R. and Newman, M.E.J. 2009. Power-law distributions in empirical data. SIAM Review, Vol. 51, no. 4: 661-703.

Cunningham, S.J. and Dillon, S.M. 1997. Authorship patterns in information systems. Scientometrics, Vol. 39, no. 1: 19-27.

de Solla-Price, D. 1976. A general theory of bibliometric and other cumulative advantage processes. Journal of the American Society for Information Science and Technology, Vol. 27, no. 5: 292-306.

DeLone, W.H. and McLean, E.R. 1992. Information Systems Success: The Quest for the Dependent Variable. Information Systems Research, Vol. 3, no. 1: 60-95.

Gao, X. and Guan, J.C. 2009. A scale-independent analysis of the performance of the Chinese innovation system. Journal of Informetrics, Vol. 3, no. 4: 321-331.

Gibrat, R. 1931. Les Inégalités économiques. Paris, France: Librairie du Recueil Sirey.

Herranz, N. and Ruiz-Castillo, J. 2012. Sub-field normalization in the multiplicative case: Highand low-impact citation indicators. Research Evaluation, Vol. 21, no. 2: 113-125.

Katz, J.S. 1994. Geographical proximity and scientific collaboration. Scientometrics, Vol. 31, no. 1: 31-43.

Katz, J.S. 1999. The self-similar science system. Research Policy, Vol. 28, no. 5: 501-517.

Katz, J.S. 2012. Scale-Independent Measures: Theory and Practice. Available at: http://www.sussex.ac.uk/spru/jskatz.

Katz, J.S. 2016. What Is a Complex Innovation System? Plos One, Vol. 11, no. 6. Available at: https://doi.org/10.1371/journal.pone.0156150.

Khor, K. A. and Yu, L. G. 2016. Influence of international co-authorship on the research citation impact of young universities. Scientometrics, Vol. 107, no. 3: 1095-1110.

Merton, R.K. 1968. The Matthew Effect in Science. Science, Vol. 159, no. 3810: 56-63.

Newman, M.E.J. 2004. Coauthorship networks and patterns of scientific collaboration. Proceedings of the National Academy of Sciences U S A Vol. 101, Supplement 1: 52005205.

Puuska, H.M., Muhonen, R. and Leino, Y. 2014. International and domestic co-publishing and their citation impact in different disciplines. Scientometrics, Vol. 98, no. 2: 823-839.

Redner, S. 1998. How popular is your paper? An empirical study of the citation distribution. The European Physical Journal B-Condensed Matter and Complex Systems, Vol. 4, no. 2: 131-134.

Ronda-Pupo, G.A. and Katz, J.S. 2017a. The scaling relationship between degree centrality of countries and their citation-based performance on Management Information Systems. Scientometrics, Vol. 112, no. 3: 1285-1299.

Ronda-Pupo, G.A., Díaz-Contreras, C., Ronda-Velázquez, G. and Ronda-Pupo, J.C. 2015. The role of academic collaboration in the impact of Latin-American research on management. Scientometrics, Vol. 102, no. 2: 1435-1454.

Ronda-Pupo, G.A. and Guerras-Martín, L.A. 2016. Collaboration network of knowledge creation and dissemination on Management research: ranking the leading institutions. Scientometrics, Vol. 107, no. 3: 917-939.

Ronda-Pupo, G.A. and Katz, J.S. 2015. The power-law relationship between citation-based performance and collaboration in articles in management journals: A scale-independent 
approach. Journal of the Association for Information Science and Technology, Vol. 67, no. 10: 2565-2572.

Ronda-Pupo, G.A. and Katz, J.S. 2017b. The Scaling Relationship between Citation-Based Performance and Scientific Collaboration in Natural Sciences. Journal of the Association for Information Science and Technology, Vol. 68, no. 5: 1257-1265.

Rousseau, R. and Ding, J. 2016. Does international collaboration yield a higher citation potential for US scientists publishing in highly visible interdisciplinary Journals? Journal of the Association for Information Science and Technology, Vol. 67, no. 4: 1009-1013.

van Raan, A.F.J. 2013. Universities scale like cities. PLoS One, Vol. 8, no. 3. Available at: https://doi.org/10.1371/journal.pone.0059384.

Wang, L., Thijs, B. and Glänzel, W. 2015. Characteristics of international collaboration in sport sciences publications and its influence on citation impact. Scientometrics, Vol. 105, no. 2: 843-862.

Wasserman, S. and Faust, K. 2009. Social Network Analysis. Methods and Applications. Edited by Structural Analysis in the Social Sciences. New York: Cambridge University Press. 
APPENDIX

Appendix 1: Management Information Systems Journals used as source for the study.

\begin{tabular}{|c|c|c|c|}
\hline JOURNAL TITLE & ISSN & COUNTRY & QUARTILE \\
\hline ACM COMPUTING SURVEYS & 0360-0300 & USA & Q1 \\
\hline ACM TRANSACTIONS ON DATABASE SYSTEMS & 0362-5915 & USA & Q4 \\
\hline ACM TRANSACTIONS ON INFORMATION SYSTEMS & $1046-8188$ & USA & Q3 \\
\hline ACM TRANSACTIONS ON THE WEB & $1559-1131$ & USA & Q3 \\
\hline BT TECHNOLOGY JOURNAL & $1358-3948$ & NETHERLANDS & Q3 \\
\hline COMMUNICATIONS OF THE ACM & 0001-0782 & USA & Q1 \\
\hline COMPUTER STANDARDS \& INTERFACES & 0920-5489 & NETHERLANDS & Q2 \\
\hline COMPUTER SYSTEMS SCIENCE AND ENGINEERING & 0267-6192 & ENGLAND & Q4 \\
\hline DATA \& KNOWLEDGE ENGINEERING & 0169-023X & NETHERLANDS & Q2 \\
\hline DATA BASE FOR ADVANCES IN INFORMATION SYSTEMS & 0095-0033 & USA & Q3 \\
\hline DECISION SUPPORT SYSTEMS & 0167-9236 & NETHERLANDS & Q1 \\
\hline DIGITAL INVESTIGATION & $1742-2876$ & NETHERLANDS & Q2 \\
\hline DISTRIBUTED AND PARALLEL DATABASES & 0926-8782 & USA & Q3 \\
\hline ELECTRONIC COMMERCE RESEARCH & $1389-5753$ & NETHERLANDS & Q3 \\
\hline ELECTRONIC COMMERCE RESEARCH AND APPLICATIONS & $1567-4223$ & USA & Q1 \\
\hline EUROPEAN JOURNAL OF INFORMATION SYSTEMS & 0960-085X & ENGLAND & Q1 \\
\hline GROUP DECISION AND NEGOTIATION & 0926-2644 & NETHERLANDS & Q2 \\
\hline IBM SYSTEMS JOURNAL & $0018-8670$ & USA & Q1 \\
\hline IEEE TECHNOLOGY AND SOCIETY MAGAZINE & 0278-0097 & USA & Q3 \\
\hline IEEE TRANSACTIONS ON KNOWLEDGE AND DATA ENGINEERING & $1041-4347$ & USA & Q1 \\
\hline IEEE TRANSACTIONS ON PROFESSIONAL COMMUNICATION & 0361-1434 & USA & Q2 \\
\hline IEICE TRANSACTIONS ON INFORMATION AND SYSTEMS & $1745-1361$ & JAPAN & Q4 \\
\hline INFORMATICA & 0868-4952 & LITHUANIA & Q2 \\
\hline INFORMATION AND ORGANIZATION & $1471-7727$ & ENGLAND & Q2 \\
\hline INFORMATION SYSTEMS & 0306-4379 & ENGLAND & Q1 \\
\hline INFORMATION SYSTEMS AND E-BUSINESS MANAGEMENT & $1617-9846$ & GERMANY & Q3 \\
\hline INFORMATION SYSTEMS FRONTIERS & $1387-3326$ & USA & Q2 \\
\hline INFORMATION SYSTEMS JOURNAL & $1350-1917$ & ENGLAND & Q1 \\
\hline INFORMATION SYSTEMS MANAGEMENT & $1058-0530$ & USA & Q3 \\
\hline INFORMATION SYSTEMS RESEARCH & $1047-7047$ & USA & Q1 \\
\hline INFORMATION TECHNOLOGY \& PEOPLE & 0959-3845 & ENGLAND & Q2 \\
\hline INFORMATION TECHNOLOGY AND CONTROL & $1392-124 X$ & LITHUANIA & Q4 \\
\hline INTERNATIONAL JOURNAL OF COOPERATIVE INFORMATION SYSTEMS & $0218-8430$ & SINGAPORE & Q4 \\
\hline INTERNATIONAL JOURNAL OF DATA WAREHOUSING AND MINING & $1548-3924$ & USA & Q4 \\
\hline INTERNATIONAL JOURNAL OF ELECTRONIC COMMERCE & $1086-4415$ & USA & Q1 \\
\hline INTERNATIONAL JOURNAL OF INFORMATION MANAGEMENT & 0268-4012 & ENGLAND & Q1 \\
\hline INTERNATIONAL JOURNAL OF MOBILE COMMUNICATIONS & 1470-949x & SWITZERLAND & Q3 \\
\hline INTERNATIONAL JOURNAL OF WEB SERVICES RESEARCH & $1545-7362$ & USA & Q4 \\
\hline IT PROFESSIONAL & $1520-9202$ & USA & Q3 \\
\hline
\end{tabular}


Ronda-Pupo, G.A.

\begin{tabular}{|c|c|c|c|}
\hline JOURNAL OF DATABASE MANAGEMENT & $1063-8016$ & USA & Q4 \\
\hline JOURNAL OF GLOBAL INFORMATION MANAGEMENT & $1062-7375$ & USA & Q4 \\
\hline JOURNAL OF INFORMATION TECHNOLOGY & 0268-3962 & ENGLAND & Q1 \\
\hline JOURNAL OF INTELLIGENT INFORMATION SYSTEMS & 0925-9902 & NETHERLANDS & Q3 \\
\hline JOURNAL OF MANAGEMENT INFORMATION SYSTEMS & $0742-1222$ & USA & Q1 \\
\hline $\begin{array}{l}\text { JOURNAL OF ORGANIZATIONAL COMPUTING AND ELECTRONIC } \\
\text { COMMERCE }\end{array}$ & 1091-9392 & USA & Q3 \\
\hline JOURNAL OF RESEARCH AND PRACTICE IN INFORMATION TECHNOLOGY & $1443-458 x$ & AUSTRALIA & Q4 \\
\hline JOURNAL OF WEB SEMANTICS & $1570-8268$ & NETHERLANDS & Q2 \\
\hline KNOWLEDGE AND INFORMATION SYSTEMS & 0219-1377 & ENGLAND & Q2 \\
\hline MIS QUARTERLY & 0276-7783 & USA & Q1 \\
\hline MIS QUARTERLY EXECUTIVE & $1540-1960$ & USA & Q3 \\
\hline MOBILE INFORMATION SYSTEMS & $1574-017 x$ & NETHERLANDS & Q2 \\
\hline NEW GENERATION COMPUTING & 0288-3635 & JAPAN & Q4 \\
\hline PERSONAL AND UBIQUITOUS COMPUTING & $1617-4909$ & ENGLAND & Q2 \\
\hline RAIRO-THEORETICAL INFORMATICS AND APPLICATIONS & 0988-3754 & FRANCE & Q4 \\
\hline TECHNICAL COMMUNICATION & 0049-3155 & USA & Q2 \\
\hline USER MODELING AND USER-ADAPTED INTERACTION & 0924-1868 & NETHERLANDS & Q1 \\
\hline VLDB JOURNAL & $1066-8888$ & GERMANY & Q1 \\
\hline WORLD WIDE WEB-INTERNET AND WEB INFORMATION SYSTEMS & $1386-145 X$ & USA & Q2 \\
\hline
\end{tabular}

Note: According to Science Metrix journal clasification scheme. 
Appendix 2: Countries according the region they are geographically located.

\begin{tabular}{|c|c|c|}
\hline Region & \multicolumn{2}{|c|}{ Country } \\
\hline Africa & $\begin{array}{c}\text { South Africa } \\
\text { Algeria } \\
\text { Tunisia } \\
\text { Nigeria } \\
\text { Libya } \\
\text { Morocco } \\
\text { Ethiopia }\end{array}$ & $\begin{array}{c}\text { Botswana } \\
\text { Kenya } \\
\text { Zimbabwe } \\
\text { Cameroon } \\
\text { Cote d'Ivoire } \\
\text { Tanzania }\end{array}$ \\
\hline Asiatic region & $\begin{array}{l}\text { China } \\
\text { Japan } \\
\text { South Korea } \\
\text { Singapore } \\
\text { India } \\
\text { Thailand } \\
\text { Malaysia } \\
\text { Hong Kong }\end{array}$ & $\begin{array}{c}\text { Pakistan } \\
\text { Indonesia } \\
\text { Bangladesh } \\
\text { Viet Nam } \\
\text { Sri Lanka } \\
\text { Philippines } \\
\text { Myanmar } \\
\text { Brunei Darussalam }\end{array}$ \\
\hline Eastern Europe & $\begin{array}{c}\text { Lithuania } \\
\text { Poland } \\
\text { Slovenia } \\
\text { Russian Federation } \\
\text { Hungary } \\
\text { Czech Republic } \\
\text { Romania } \\
\text { Serbia } \\
\text { Croatia } \\
\end{array}$ & $\begin{array}{c}\text { Ukraine } \\
\text { Bulgaria } \\
\text { Estonia } \\
\text { Latvia } \\
\text { Yugoslavia } \\
\text { Albania } \\
\text { Belarus } \\
\text { Bosnia and Herzegovina } \\
\text { Montenegro } \\
\end{array}$ \\
\hline Latin America & $\begin{array}{c}\text { Brazil } \\
\text { Chile } \\
\text { Mexico } \\
\text { Argentina } \\
\text { Colombia } \\
\text { Venezuela } \\
\text { Jamaica } \\
\text { Cuba } \\
\end{array}$ & $\begin{array}{c}\text { Peru } \\
\text { Trinidad and Tobago } \\
\text { Netherlands Antilles } \\
\text { Costa Rica } \\
\text { Paraguay } \\
\text { Guatemala } \\
\text { West Indies Associated States } \\
\text { Barbados } \\
\end{array}$ \\
\hline Northern America & United States & Canada \\
\hline Pacific region & $\begin{array}{c}\text { Australia } \\
\text { New Zealand }\end{array}$ & $\begin{array}{c}\text { Fiji } \\
\text { New Caledonia }\end{array}$ \\
\hline
\end{tabular}


Ronda-Pupo, G.A.

\begin{tabular}{|c|c|c|}
\hline Middle East & $\begin{array}{c}\text { Israel } \\
\text { Turkey } \\
\text { Iran } \\
\text { United Arab Emirates } \\
\text { Saudi Arabia } \\
\text { Egypt } \\
\text { Lebanon } \\
\end{array}$ & $\begin{array}{c}\text { Kuwait } \\
\text { Jordan } \\
\text { Oman } \\
\text { Syrian Arab Republic } \\
\text { Qatar } \\
\text { Bahrain }\end{array}$ \\
\hline Western Europe & $\begin{array}{l}\text { United Kingdom } \\
\text { Germany } \\
\text { Italy } \\
\text { Netherlands } \\
\text { France } \\
\text { Spain } \\
\text { Greece } \\
\text { Finland } \\
\text { Switzerland } \\
\text { Denmark }\end{array}$ & $\begin{array}{l}\text { Belgium } \\
\text { Austria } \\
\text { Sweden } \\
\text { Norway } \\
\text { Ireland } \\
\text { Portugal } \\
\text { Cyprus } \\
\text { Iceland } \\
\text { Luxembourg } \\
\text { Liechtenstein }\end{array}$ \\
\hline
\end{tabular}

Note: Classification according to Scimago Group. 